\title{
Crystalline organization of the fibrous prismatic calcitic layer of the Mediterranean mussel Mytilus galloprovincialis
}

\author{
ANTONIO G. CHECA ${ }^{1, *}$, CARLOS M. PINA ${ }^{2,3}$, ANTONIO J. OSUNA-MASCARÓ ${ }^{1}$, \\ ALEJANDRO B. RODRÍGUEZ-NAVARRO ${ }^{4}$ and ELIZABETH M. HARPER ${ }^{5}$
}

\author{
${ }^{1}$ Departamento de Estratigrafía y Paleontología, Universidad de Granada, 18071 Granada, Spain \\ *Corresponding author, e-mail: acheca@ugr.es \\ ${ }^{2}$ Departamento de Cristalografía y Mineralogía, Universidad Complutense de Madrid, 28040 Madrid, Spain \\ ${ }^{3}$ Instituto de Geociencias (UCM-CSIC), 28040 Madrid, Spain \\ ${ }^{4}$ Departamento de Mineralogía y Petrología, Universidad de Granada, 18071 Granada, Spain \\ ${ }^{5}$ Department of Earth Sciences, University of Cambridge, Cambridge CB2 3EQ, UK
}

\begin{abstract}
The outer layer of the shell of members of the genus Mytilus is made of long, slender fibres of calcite (some 1-2 $\mu$ m wide and hundreds of $\mu \mathrm{m}$ long), which reach the internal surface of the shell at an angle. This microstructure has been called anvil-type fibrous calcitic and its organization, crystallography and relationships to the organic phase are poorly known. We have studied the outer calcitic layer of the Mediterranean mussel M. galloprovincialis by means of optical and scanning and transmission electron microscopy (SEM and TEM), X-ray diffraction (XRD) and atomic-force microscopy (AFM). SEM data from other species have also been gathered. All data together imply that the material is extremely well ordered both from the morphological and crystallographic viewpoints. The XRD pole figures show that there are discrete 001 and 104 maxima; therefore, the material has a well-defined sheet texture. In living animals there is an organic membrane (surface membrane) that coats the inner surface of the shell. TEM sections of the decalcified material show that this mainly proteinaceous surface layer is internally laminated and fills all the spaces left between the growing fibres. Every fibre is a monocrystal with three well developed $\{104\}$ rhombohedral faces at its growth end. One of these faces is directly in contact with, and strictly parallel, to the sublayers of the surface membrane and thus to the inner shell surface. AFM experiments consisting on growing calcite onto shell pieces in which the surface membranes are preserved, show that the calcitic fibres of the shell easily regrow across the membrane, demonstrating that it is permeable to ions. In this way, prisms are able to grow despite the existence of the intermediate membrane in the living animal. Additional experiments of calcite growth onto the inner side of the surface membrane show that crystals grow onto their $\{104\}$ surfaces. The surface membrane is responsible for the high degree of ordering of the fibrous calcitic layer, because it stabilizes the orientation of a rhombohedral surface, once this is parallel to the protein sublayers. This is one of the very few cases in which the influence of the organic matter on the organization of microstructures can be demonstrated.
\end{abstract}

Key-words: microstructure, crystal growth, calcite, texture, biomineralogy, X-ray, SEM, TEM, AFM, molluscs, bivalves, Mytilus.

\section{Introduction}

The outer layer of the shell of members of the genus Mytilus is made of long, slender fibres of calcite (some $1-2 \mu \mathrm{m}$ wide and tens of $\mu \mathrm{m}$ long), which reach the inner surface of the shell at an angle. This microstructure has been called anvil-type calcitic fibrous prismatic (Carter, 1990; Carter et al., 2012) and, although it is not universal, it occurs in many other genera of the Mytilidae (the only family of the Mytiloida), in particular in many of those inhabiting temperate seas.

Although the significance of the occurrence of an outer calcitic layer in mussels has been widely discussed (Lowenstam, 1954a and b; Carter, 1980; Carter \& Seed, 1998), this microstructure has received comparatively little attention. In particular there has been little study of how this microstructure differs from other 'prismatic' calcite microstructures found in other bivalves. This is of interest as there appears to be considerable variation in prism microstructure [i.e. between the blocky prisms of pterioids (Checa et al., 2005), the foliated prisms in ostreoids and pectinoids (Esteban-Delgado et al., 2008) and the very distinctive, and as yet uncharacterised, prisms of some chamids (Taylor \& Kennedy, 1969)].

The crystallography of the fibrous calcitic layer of the blue mussel M. edulis was investigated with TEM by Feng et al. (2000) and with SEM and electron backscatter diffraction (EBSD) by Dalbeck et al. (2006). With small differences, both studies arrived at the same conclusions: that the $c$-axis 
is parallel to the long axis of the fibres and that there is a face belonging to the $\{104\}$ rhombohedra parallel to the internal shell surface (Feng et al., 2000), or to the calcite-nacre interface (Dalbeck et al., 2006). A similar pattern is deduced from the XRD study of Chateigner et al. (2002) on the deep-sea mussel Bathymodiolus thermophilus. In more detail, Feng et al. (2000) suggested that all calcite fibres had their $\{104\}$ faces parallel to the internal surface of the shell, but that they were distributed into clusters of 1-5 fibres and that each cluster had a particular orientation of the $\{104\}$ face; in this way, the $c$-axes of the fibres could not be strictly aligned. The different pole figures provided by Dalbeck et al. (2006) showed a tight clustering of the maxima, which increased from close to the outer surface to the boundary with the nacre. The main conclusion is that the fibrous prismatic layer of mytilids is a perfectly organized material, which displays a sheet texture (i.e., the crystallographic axes are evenly aligned in the three directions perpendicular to the $c$ axis). Some microstructures display fibre textures, with the $c$ axes of either calcite (e.g., prismatic calcite; Checa \& Rodríguez-Navarro, 2005; Checa et al., 2005) or aragonite crystals (granular homogeneous, gastropod nacre and Nautilus; Hedegaard \& Wenk, 1998; Chateigner et al., 2000, 2002; Harper et al., 2009) being parallel, but with the rest of the axes rotated. Sheet textures have been described in the nacres of bivalves and Nautilus (Wada, 1961; Wise, 1970; Hedegaard \& Wenk, 1998; Chateigner et al., 2000; Checa \& Rodríguez-Navarro, 2005), the crossed lamellar microstructures of bivalves and gastropods (Hedegaard \& Wenk, 1998; Chateigner et al., 2000) and in the foliated calcite of ostreoids and pectinoids (Checa et al., 2007). Although the case of bivalve nacre was explained by Checa et al. (2006) as being due to competition between nacre platelets, this model cannot be universal, because it only applies when nacre plates are elongated along the $b$-axis. In the case of foliated calcite the folia are made of lath-like calcitic units distributed into lamellae. Ordering of the laths within the lamellae with their long axis in the growth direction can be explained by selection by competition.

Selection by competition in the fibrous calcite of mytilids could explain the fact that all fibres grow with their long axis parallel to the growth direction, but not the fact that all rhombohedral faces are evenly oriented. In order to establish the origin of such ordering, we have studied shells of living specimens of the Mediterranean mussel M. galloprovincialis Lamarck, 1819, by means of optical and electron microscopy (SEM and TEM), XRD and AFM. Our results imply that the associated organic matter is crucial in the 3D organization of the material. This is one of the few cases in which the influence of the organic matter on the crystallographic organization of microstructures has yet been demonstrated.

\section{Material and techniques}

\subsection{Material examined}

Our main study animal was $M$. galloprovincialis. Living juveniles $(15-25 \mathrm{~mm})$ were sampled in the intertidal of
Lagos and Sagres (Algarve, Portugal) and adults (> $64 \mathrm{~mm}$ ) purchased commercially (Coast of Galicia, NW Spain). For comparative purposes dry shells of other mytilids possessing calcitic outer shell layers were also examined: M. edulis platensis d'Orbigny, 1842 (reported frequently under the synonym $M$. chilensis Hupé, 1854) (Punta Huinay, Chile [42²2'20'" S 72 $25^{\prime} 40^{\prime \prime}$ W]), M. californianus Conrad, 1837 (Goleta Beach, Santa Barbara County, California [ $34^{\circ} 25^{\prime} 00^{\prime \prime} \mathrm{N}, 119^{\circ} 49^{\prime} 54^{\prime \prime} \mathrm{W}$ ], collected by Paul Valentich-Scott 2nd July 2008), Bathymodiolus azoricus Cosel \& Comtet, 1999 (Lucky Strike hydrothermal vent field on the Mid-Atlantic Ridge; depth $\sim 1800 \mathrm{~m}$ ) and Choromytilus chorus (Molina, 1782) (bought on market at Puerto Montt, Chile 18th March 2008).

\subsection{Electron and optical microscopy}

Specimens used for scanning (SEM) and transmission electron microscopy (TEM) were juveniles of $M$. galloprovincialis. They were fixed in vivo $(2.5 \%$ glutaraldehyde, buffered with cacodylate $0.1 \mathrm{M}, \mathrm{pH}$ 7.4) and maintained at $4^{\circ} \mathrm{C}$.

Specimens observed in SEM were previously critically point dried and coated with carbon (Hitachi UHS evaporator). We used the field emission SEM (FESEM) Zeiss LEO Gemini 1530 as well as the Zeiss Auriga Cross-Beam Station. Some dry shells were examined with the desktop SEM Phenom G2 Pro. Specimens for optical microscopy and TEM were completely decalcified ( $2 \%$ EDTA), postfixed in $\mathrm{OsO}_{4}(2 \%)$ for $2 \mathrm{~h}$ at $4{ }^{\circ} \mathrm{C}$ and embedded in epoxy resin Epon 812 (EMS). Sections were obtained with an ultramicrotome Leica Ultracut R. Semi-thin sections $(\sim 0.5 \mu \mathrm{m})$ were stained with $1 \%$ toluidine blue and observed and photographed with an Olympus BX51 microscope. Ultra thin sections $(50 \mathrm{~nm})$ were stained with uranyl acetate $(1 \%)$ followed by lead citrate. They were later carbon-coated and observed with TEM (Zeiss Libra 120 Plus). All instrumentation is housed at the University of Granada.

\subsection{X-ray diffraction}

Pole figures representing the orientation of specific $\{\mathrm{hkl}\}$ planes relative to the sample were determined using an X-ray single-crystal diffractometer equipped with a CCD area detector (D8 SMART APEX, Bruker, Germany). For diffraction experiments, the working conditions were: Mo $K \alpha(\lambda=0.7093 \AA), 50 \mathrm{kV}$ and $30 \mathrm{~mA}$, a pin-hole collimator of $0.5 \mathrm{~mm}$ in diameter, and an exposure time of $20 \mathrm{~s}$ per frame. The diffractometer $\omega$ and $2 \theta$ angles were set at $10^{\circ}$ and $20^{\circ}$ respectively to measure the samples by reflection mode. The analyses were made on the inner surface of the sample, some $2-3 \mathrm{~mm}$ inwards from the growth margin. In this way, we were sure that only fibrous calcite was measured. A set of 2D-diffraction patterns was registered while rotating the sample around $\Phi$ angle (a frame every $5^{\circ}$ was registered). Pole densities/figures for main calcite 
reflections were measured from the registered frames using XRD2DScan software (Rodríguez-Navarro, 2006). Samples of the interior of the shell margin (placed horizontal) of adult $M$. galloprovincialis, $M$. californianus, $M$. edulis platensis, B. azoricus and C. chorus were analysed in this way.

\subsection{AFM fluid-cell experiments}

The AFM observations were made at room temperature with the a Multimode IIIa (Veeco Instruments) microscope equipped with a fluid cell at the Centro Nacional de Microscopía Electrónica in Madrid. The AFM images were obtained in contact mode using a $\sim 14 \times 14 \mu \mathrm{m}^{2}$ scanner and silicon nitride tips supported by triangular cantilevers (Bruker SNL-10). Height, deflection and friction images of the internal part of the shell fragments were recorded. As previously shown, the high quality of friction images taken in water allows one to easily resolve the crystal lattice on calcite $\{104\}$ surfaces (Pina et al., 2012). The size of images varied from $\sim 14 \times 14 \mu \mathrm{m}^{2}$ to $5 \times 5 \mathrm{~nm}^{2}$ (images with atomic resolution). The analysis of all the AFM images was performed with the Nanoscope (5.30r3sr3) and WSxM 4.0 softwares (Horcas et al., 2007). Two experiments were performed to investigate the role of the organic membranes on crystal growth and orientation.

\subsubsection{Internal shell surfaces of living specimens}

Two adult specimens were kept alive up to the initiation of the experiment. Using a cutting disc coupled to a Multi Dremel $^{\circledR}$ mini drill, a piece of shell was cut from the shell margin, from the area of calcite secretion, and was placed immediately in the fluid cell of the AFM. Care was taken that the internal shell surface (and, hence, its associated surface membrane) was exposed. Deionised water (MilliQ; $18 \mathrm{M} \Omega \cdot \mathrm{m})$ and subsequently a $\mathrm{CaCO}_{3}$ aqueous solution with a concentration of $1.2 \mathrm{mmol} / \mathrm{l}$ were injected into the fluid cell. The $\mathrm{CaCO}_{3}$ solution was prepared by mixing high-purity $\mathrm{Na}_{2} \mathrm{CO}_{3}$ and $\mathrm{CaCl}_{2}$ solutions and deionised water. The supersaturation of this solution with respect to calcite was $\beta_{\text {calcite }}=\left[a\left(\mathrm{Ca}^{2+}\right) a\left(\mathrm{CO}_{3}{ }^{2-}\right) / K_{s p \text {, calcite }}\right]=69$, where $K_{s p, \text { calcite }}=10^{-8.48}$ is the solubility product of calcite, and $a\left(\mathrm{Ca}^{2+}\right)$ and $a\left(\mathrm{CO}_{3}{ }^{2-}\right)$ are the activities of the ions in the aqueous solution. These activities were calculated using the PHREEQC computer code and the PHREEQC.DAT data base (Parkhurst \& Appelo, 1999).

\subsubsection{Isolated surface membranes of the calcitic layer}

A set of 20 adult specimens of $M$. galloprovincialis was used to extract the surface membranes. They were decalcified in a medium which was adjusted to $\mathrm{pH} 4$, starting from a solution of $10 \%$ acetic acid. This $\mathrm{pH}$ values permits decalcification without denaturing the proteins (Marin, 2003). During decalcification, solution was constantly added in order to keep the $\mathrm{pH}$ constant. When shells were completely decalcified, we selected the three best preserved, from which the surface membrane was manually excised under the binocular microscope. The membranes were immersed again in the acetic solution at $\mathrm{pH} 4$ for 1 minute and then kept at $4^{\circ} \mathrm{C}$ in Milli Q water until the experiments were performed.

Surface membranes were later placed under the AFM ensuring that the exposed surface was that originally facing towards the growing calcite crystals. Two solutions were prepared and tested according to the above protocol although with different concentrations:

\begin{tabular}{|c|c|c|c|c|c|c|}
\hline $\begin{array}{l}{\left[\mathrm{Ca}^{2+}\right]} \\
{\left[\mathrm{Na}^{+}\right]} \\
\mathrm{pH}_{\text {measu }}\end{array}$ & $\begin{array}{cc}= & 0.75 \\
= & 1.5 \\
\text { ed }= & 10.47\end{array}$ & $\begin{array}{c}\mathrm{mmol} / \mathrm{l} ; \\
\mathrm{mmol} / \mathrm{l} ; \\
\beta_{\text {calcite }}=\end{array}$ & $\begin{array}{c}{\left[\mathrm{CO}_{3}{ }^{2-}\right]} \\
{\left[\mathrm{Cl}^{-}\right]} \\
34.7 .\end{array}$ & $\begin{array}{l}= \\
=\end{array}$ & $\begin{array}{l}0.75 \\
1.5\end{array}$ & $\begin{array}{l}\mathrm{mmol} / \mathrm{l} ; \\
\mathrm{mmol} / \mathrm{;}\end{array}$ \\
\hline $\begin{array}{l}{\left[\mathrm{Ca}^{2+}\right]} \\
{\left[\mathrm{Na}^{+}\right]}\end{array}$ & $\begin{array}{ll}= & 1.5 \\
= & 3.0\end{array}$ & $\begin{array}{c}\mathrm{mmol} / \mathrm{l} ; \\
\mathrm{mmol} / \mathrm{l}\end{array}$ & $\begin{array}{c}{\left[\mathrm{CO}_{3}{ }^{2-}\right]} \\
{\left[\mathrm{Cl}^{-}\right]}\end{array}$ & $\begin{array}{l}= \\
=\end{array}$ & $\begin{array}{l}1.5 \\
3.0\end{array}$ & $\begin{array}{l}\mathrm{mmol} / \mathrm{l} ; \\
\mathrm{mmol} / \mathrm{l} ;\end{array}$ \\
\hline
\end{tabular}

The experiment was terminated after a little more than one hour after which we checked whether any crystal growth had finally occurred. The samples were later allowed to air dry and observed under FESEM (Zeiss Auriga CrossBeam Station).

\section{Results}

\subsection{Scanning electron microscopy}

The fibrous calcite layer of $M$. galloprovincialis is made of calcite fibres with diameters of 1-2 $\mu \mathrm{m}$ and lengths of many tens of $\mu \mathrm{m}$ (Fig. 1a-d). They have triangular to rounded sections and impinge with each other, except from some $2-3 \mu \mathrm{m}$ before their tips at the inner surface of the valve, where they become slender (Fig. 1e). Fibres typically develop rhombohedral endings (Fig. 1c, d). The faces of neighbouring fibres are evenly aligned, although small misorientations can sometimes be perceived. Some fibres are in the process of fusion or division (Fig. 1c, d). One of the rhombohedral faces is always facing upwards towards the shell's internal surface (Fig. 1d). In some areas, away from the shell margin, the fibres are extremely even in size and well ordered, being distributed into layers, with fibres of superposed layers being completely offset (Fig. 1b-d). Towards the margin, the differences in size and the degree of disorder increase. In one juvenile specimen, the orientation of the fibres with respect to the margin is approximately, though not strictly, radial, except at the anterior-ventral (almost antimarginal) and anterior (comarginal) margins (Fig. 2)

The transition to the nacre is gradual, with occasional incipient tablets being first secreted onto the fibres. The density of tablets increases towards the shell interior until the transition to nacre is completed (Fig. 1f).

In the in vivo fixed and critically-point dried specimens, a membrane is observed on top of the fibrous layer (Fig. 1g-i). The observed thickness of the dried membrane is around 40-50 nm (Fig. 1h) and the appearance is that of a fibrous felt, with fibres being about $20-40 \mathrm{~nm}$ in diameter and showing no apparent 

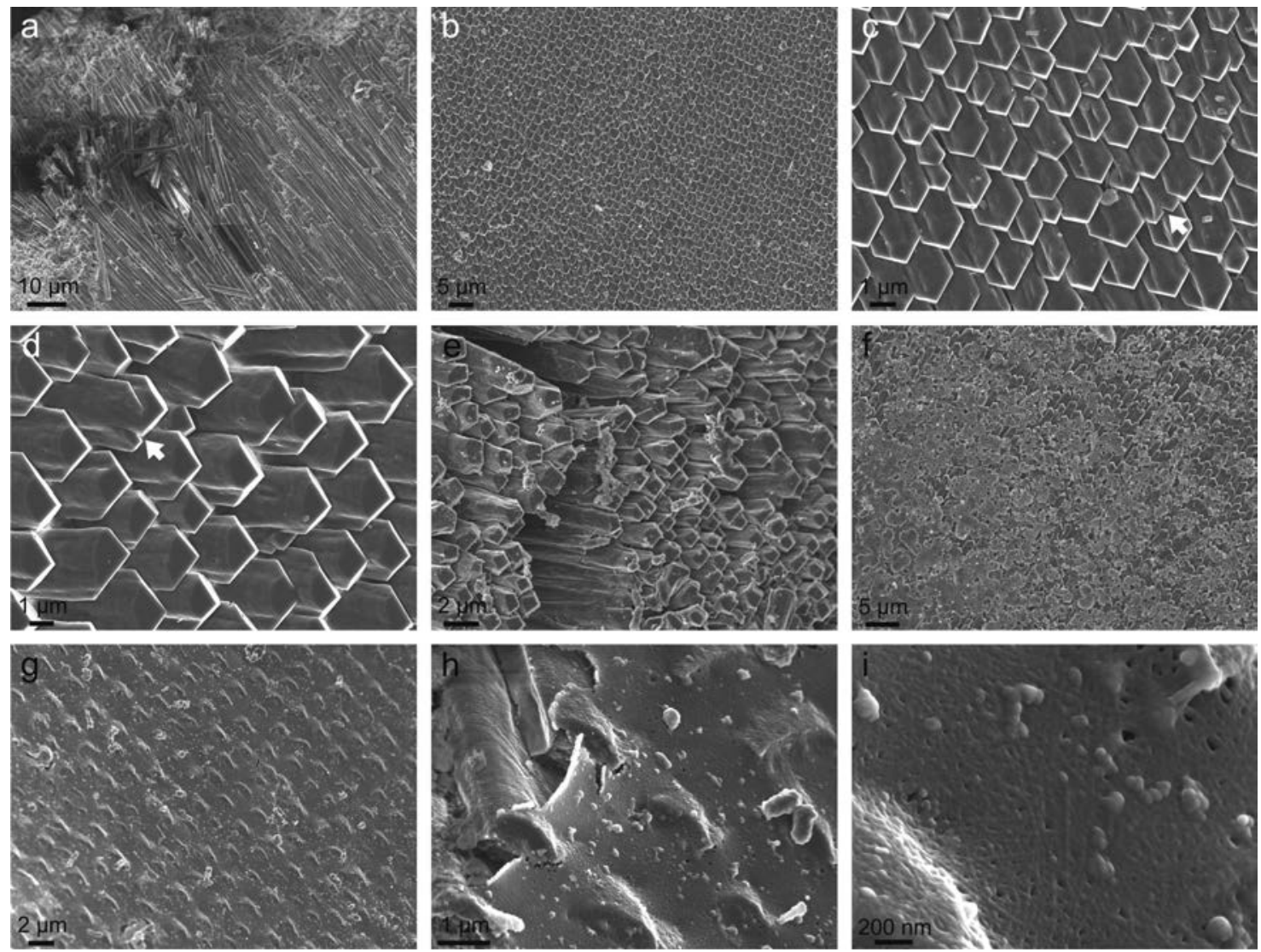

Fig. 1. Calcitic fibrous layer of M. galloprovincialis. (a) Fracture parallel to the fibres, close to the shell margin. (b) Far view of the internal shell surface showing the high degree of ordering of the fibres. (c) Close up of the internal surface of the fibrous layer. The arrow points to a dividing fibre. (d) Same as in Fig. 1c. The rhombohedral faces parallel to the internal surface are evident. The arrow points to a dividing fibre. (e) Slightly fractured calcitic layer. Note that fibres widen from the tip backwards until they impinge with each other. (f) Transition from the calcitic layer to the nacre. The nacre cover increases towards the bottom left. (g) General view of the dehydrated surface membrane, with the bulging underlying fibres. (h) Close up of the broken membrane showing its extreme thinness. (i) Fibrous aspect of the dehydrated surface membrane.

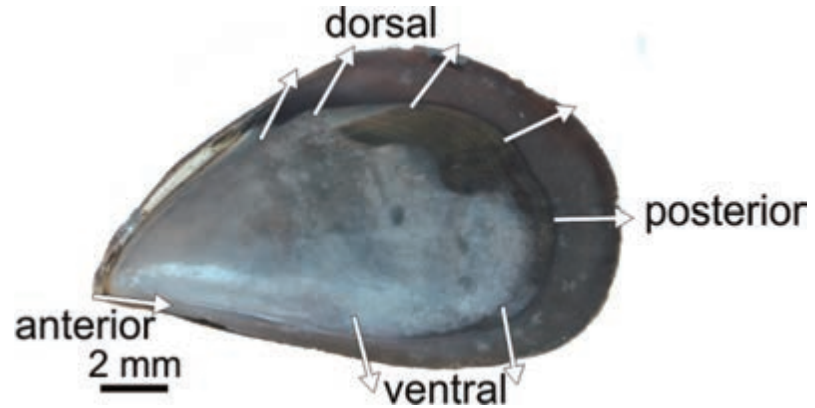

Fig. 2. Orientations (arrows) of the fibres along the shell margin of a juvenile specimen of $M$. galloprovincialis. The orientations were estimated by SEM.

alignment (Fig. 1i). This membrane will be called surface membrane, by analogy with the nacre surface membrane first observed in gastropods by Nakahara (1991). The surface membrane is continuous all along the fibrous layer surface and encloses completely the compartment of the layer formation.
In the other species examined, the highest degree of irregularity has been observed in B. azoricus, with fibres being very uneven in diameter, initiating, dividing or disappearing during growth (Fig. 3a-d). Close to the edge, some bundles may suddenly change their orientation (Fig. $3 c)$. Eventually, fibres were observed to twist around their long axis (Fig. 3c). In C. chorus (Fig. 3e, f) and M. edulis platensis (Fig. 3g, h) the size and arrangement of fibres is very similar to the one described for M. galloprovincialis, with cases of bending fibres being recorded (Fig. 3f). In all three species, the fibres have their rhombohedral faces aligned in parallel (Fig. 3b-d, f-h). The most unusual fibre shapes have been recorded in M. californianus (Fig. $3 i)$, in which the endings of fibres are very poorly developed rhombohedral to apparently pinacoid $(\{001\})$.

\subsection{Optical microscopy and TEM}

Optical micrographs of decalcified specimens show that fibres are arranged at an angle of some $45^{\circ}$ to the internal shell surface (Fig. 4a, b). This orientation is naturally 

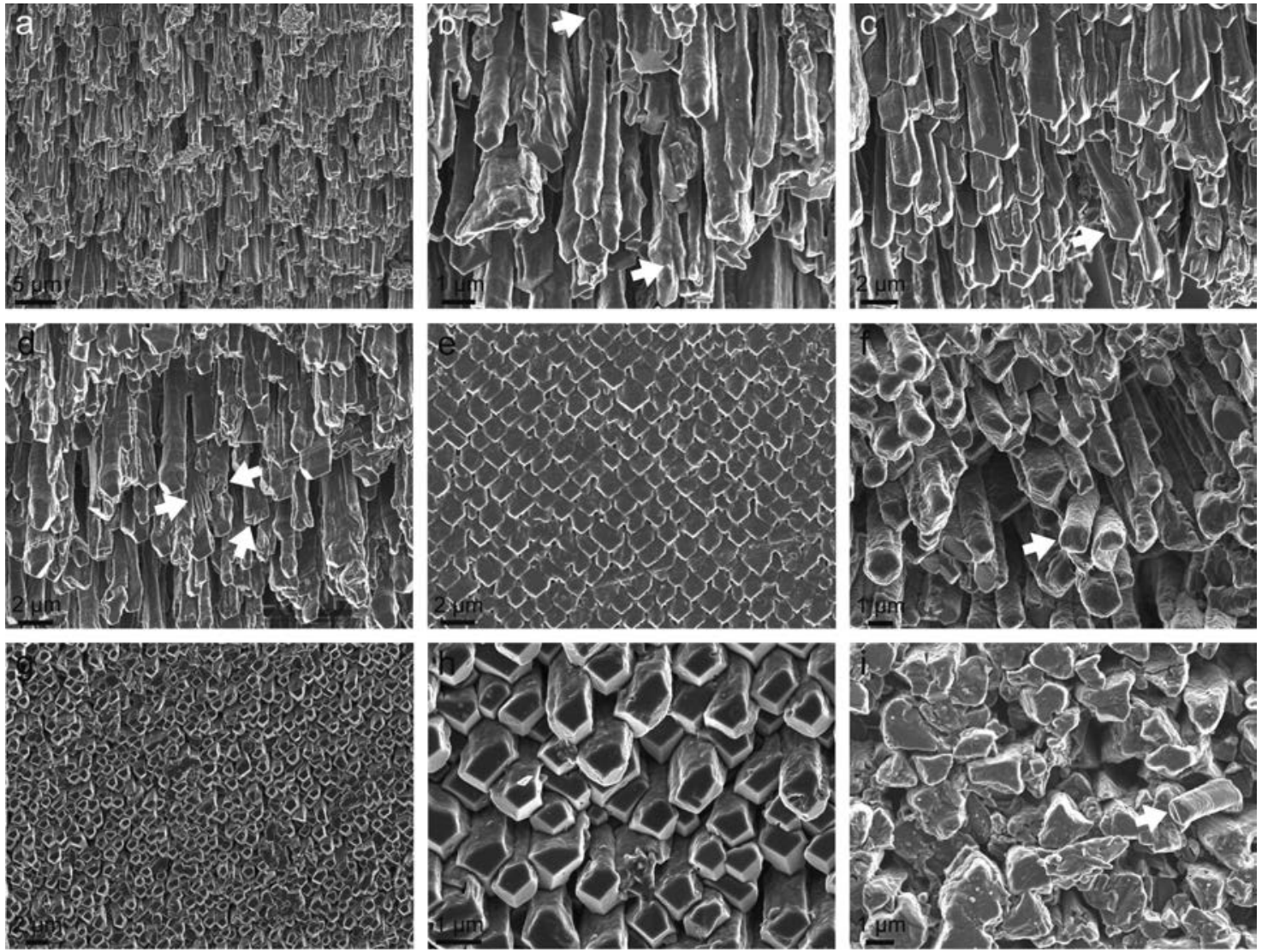

Fig. 3. Calcitic fibrous layers of adult mytilids. (a-d) Fibrous layer of B. azoricus. (a) General view showing the high irregularity in size of fibres. (b-d) Details of fibres. The arrows point to newly formed (b), twisting (c) or splitting fibres (b, d). (e, f) C. chorus. (e) General view of the layer showing the high regularity in size and distribution (compare to Fig. 1b). (f) Detail of the same layer close to the margin. The arrow points to bending fibres. (g-h) M. edulis platensis. General view and detail of the fibrous layer. Note the even orientation of rhombohedral faces in (h). (i) M. californianus. Fibres are characterized by irregular outlines and endings. The arrow indicates a bent fibre.

retained with respect to the internal growth lines, which represent the positions of older shell surfaces (Fig. 4a).

The TEM analysis of the decalcified material of $M$. galloprovincialis shows how the fibres initiate at apparently spherulitic bodies within the periostracum, although their initial arrangement is slightly disordered (Fig. 4c). The views of the internal shell surface clearly show both the surface membrane and the organic sheaths that envelop the calcitic fibres (Fig. $4 \mathrm{~d}-\mathrm{g}$ ). The surface membrane is internally patterned into parallel horizontal nanolaminae, which are spaced at $c a .100 \mathrm{~nm}$ (Fig. $4 \mathrm{~d}-\mathrm{g}$ ). It is totally continuous onto the successive fibres. Its thickness is minimal (200-300 nm) onto the flat horizontal surfaces of the fibres, which correspond to the upward-looking rhombohedral faces and which are strictly parallel to the surface membrane and its laminae. The surface membrane also fills the spaces between the growing tips of the fibres, where the nanolaminae appear disturbed. The fibres of calcite are surrounded by organic sheaths $(\sim 40 \mathrm{~nm}$ thick), which are continuous all around them. The terminal thinning of fibres from the point where they impinge with each others to their tips is also evident in some sections (Fig. 4d).

\subsection{X-ray diffraction}

Pole figures of $M$. galloprovincialis show particular and well defined patterns. First, the degree of scattering of the maxima is very reduced (Fig. 5a). The 001 maximum (which corresponds to the $c$-axis of calcite crystals) is displaced from the centre of the pole figure in the growth direction of the fibres for some more than $40^{\circ}$ and there is always a 104 pole maximum very close to or at the centre of the diagram, indicating that a $\{104\}$ face is parallel to the inner shell surface. Therefore, the positions of maxima in the pole figures change depending on the orientation of the fibres along the shell margin (compare Fig. 2-5a). The same patterns appear in the rest of the examined species of mytilids analyzed, the main differences lying in the degree of scattering of pole maxima (Fig. 5b). The maximum scattering was observed in M. californianus, where the 

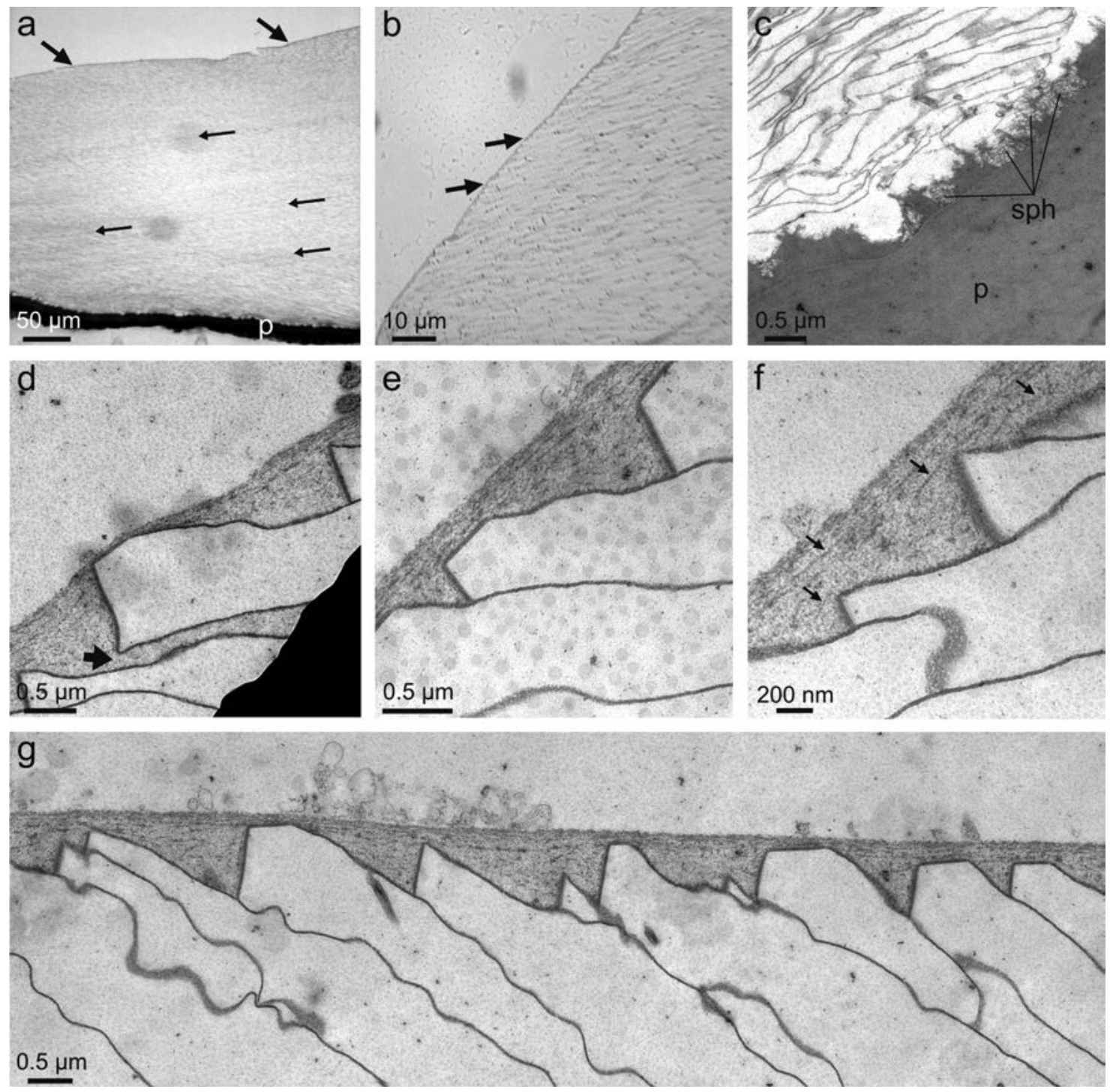

Fig. 4. (a-b) Optical micrographs of a decalcified shell of M. galloprovincialis. The thick dark layer is the periostracum (p). (a) General view of a transversal section. The growth margin is to the left. Thick arrows indicate the orientation of decalcified fibres and thin arrows indicate the orientation of growth lines. (b) Detail of the internal shell surface. The fibres reach the surface at some $45^{\circ}$ (arrows indicate their orientation). (c-g) TEM micrographs of the same shell. (c) View of the initiation of the fibres, in contact with the periostracum (p). Fibres initiate from spherulitic bodies (sph). (d-g) Views of the internal shell surface. In all of them the covering surface membrane with its internal nanolaminated aspect is evident (particularly in Fig. 4f, where the nanolaminae are indicated with arrows). The flat surface parallel to the surface membrane is a rhombohedral face. The outlines of fibres are marked by organic sheaths which have wrinkled upon decalcification. The arrow in Fig. 4d indicates a fibre which is not in contact with its neighbours.

distribution is close to that of a fibre-like texture, whereas the more restricted maxima of all measured species correspond to C. chorus.

\subsection{Crystal growth observed by AFM}

\subsubsection{Internal shell surfaces of living specimens}

Fragments of shells of freshly killed specimens under AFM allow us to observe that the surface organic layer has a flat and homogeneous surface with occasional smooth large wrinkles, which correspond to the outlines of the underlying fibres. In even closer view, the organic layer shows a nanorippled surface (Fig. 6a).

More than one hour after a $\mathrm{CaCO}_{3}$ supersaturated solution was injected in the AFM fluid cell, the surface membranes became imprinted with the shapes of the rhombohedral faces of the underlying calcite fibres (Fig. $6 b)$. Finally, typical rhombohedral calcite crystals were directly imaged; they correspond to the piercing through the surface membrane of the regrown calcite fibres (Fig. $6 c, d)$. This indicates that regrowth on the calcitic prismatic fibres is promoted by the highly supersaturated $\mathrm{CaCO}_{3}$ solution that permeates through the porous organic layer. 


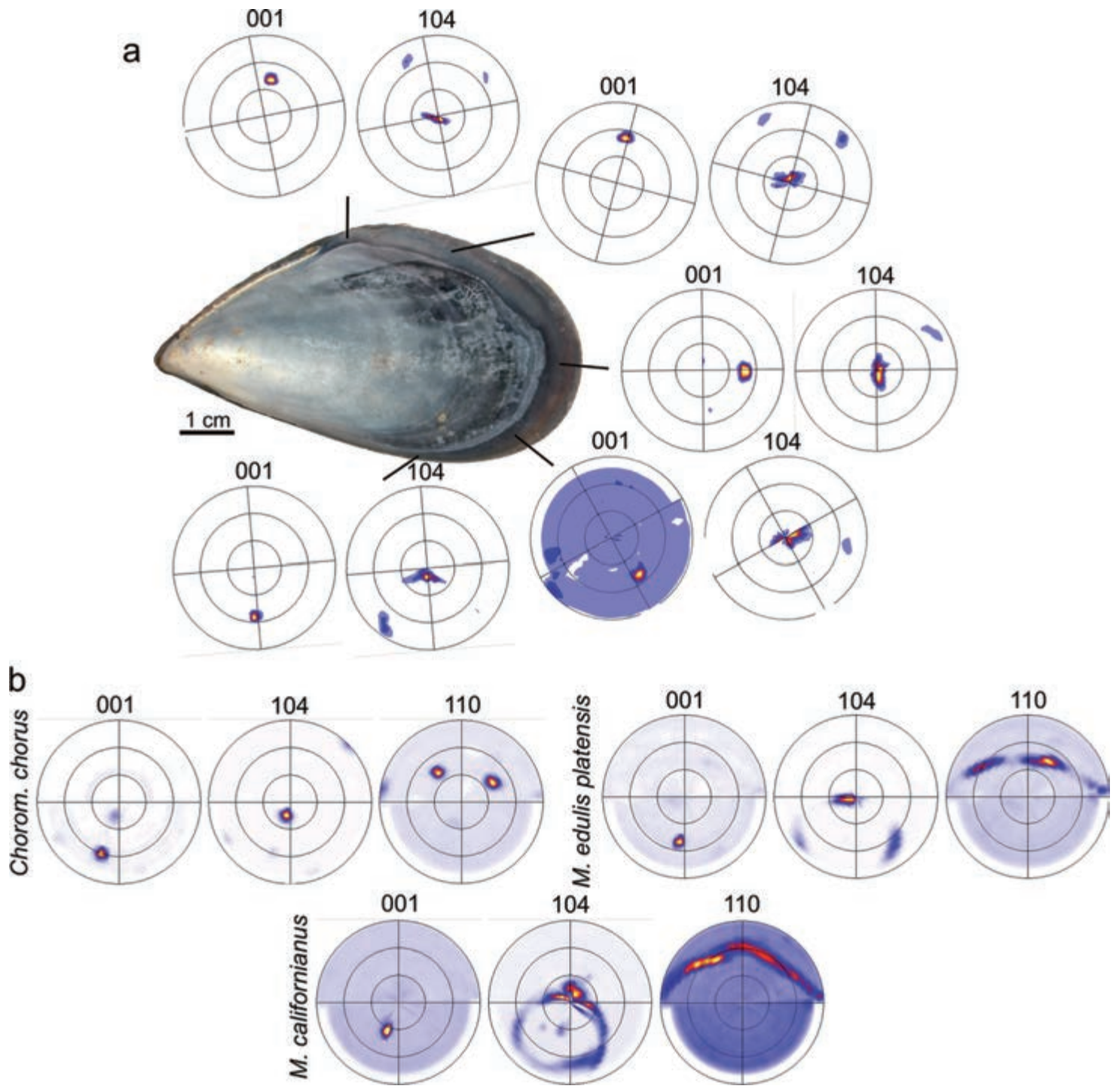

Fig. 5. (a) 001 and 104 pole figures at various positions along the margin of a specimen of M. galloprovincialis. Note that the 001 maximum is advanced in the direction of growth of fibres nearly perpendicular to the shell margin (compare to Fig. 2) and that the 104 maximum is centred on the pole diagram. (b) 001, 104 and 110 pole figures for three species of Mytilidae. The measurements were taken at the ventral margin and the growth direction is towards the bottom. Note the tight clustering of maxima in M. edulis platensis (see Fig. $3 \mathrm{~g}$ and $\mathrm{h}$ ) and, particularly, in C. chorus (see Fig. 3e), and the high scattering in M. californianus (see Fig. 3i).

In this process, the surface membrane becomes pushed and destroyed and bits of it remain attached to the surfaces of upper rhombohedral surface. Although the loading force was intentionally decreased to reduce the interaction between the AFM tip and the surface, once the organic membrane is broken around the crystals, it is easily removed by the AFM tip after a few scans.

Figure 6e shows the arrangement of calcite rhombohedra once the organic layer is almost completely removed. The size of such rhombohedra is quite uniform $(1-2 \mu \mathrm{m})$ and they exhibit an almost perfect periodic pattern. By measuring on the 2D-Fast Fourier Transform map, periodicities of $\sim 1.6 \mu \mathrm{m}$ along the horizontal bisectrix of the rhombohedra (i.e. the [421] direction) and of $\sim 1.8 \mu \mathrm{m}$ along their edges (i.e. the [ $\overline{4} 41]$ and $[48 \overline{1}]$ directions) have been obtained
(Fig. 6e, inset). The parallelism between $\{104\}$ calcite faces and the organic layer is confirmed by the AFM images. The topography of a transect through two of calcite rhombohedra shows that the upper $\{104\}$ faces are perfectly horizontal (Fig. 6f, g). High-resolution friction AFM images of the horizontal $\{104\}$ faces reveal a rectangular lattice with dimensions $a \sim 0.8 \mathrm{~nm}$ and $b \sim 0.5 \mathrm{~nm}$, similar to that observed on the same faces of inorganic calcite crystals using the same technique (Fig. 6h) (e.g., Stipp, 1999; Rode et al., 2009; Schütte et al., 2010; Pina et al., 2012).

\subsubsection{Isolated surface membranes of the calcitic layer}

In the second set of experiments, the underside of the isolated membrane was exposed to the supersaturated 

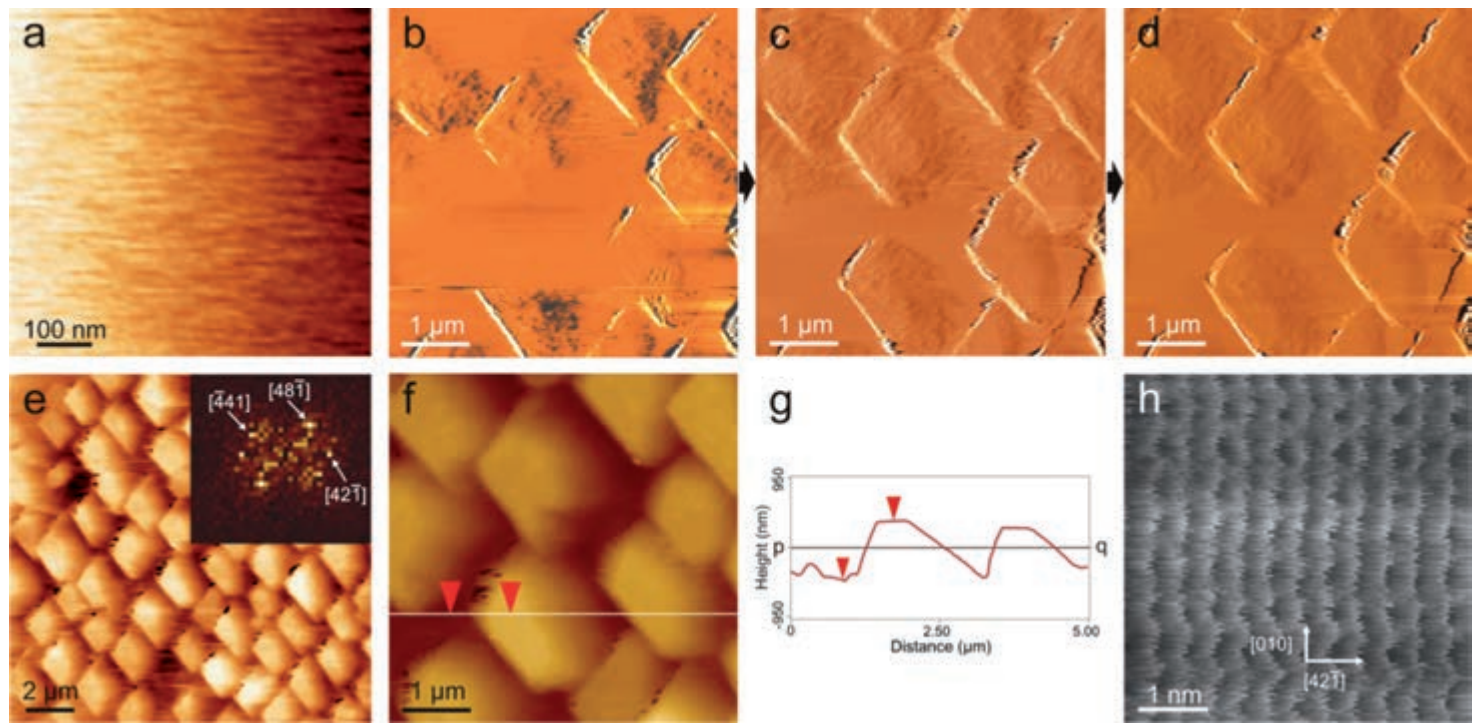

Fig. 6. AFM observations in fluid cell of a shell fragment covered with the original surface membrane submerged in a supersaturated solution $\left(\beta_{\text {calcite }}=69\right)$. (a) Detail of the rippled surface of the organic layer of $M$. galloprovincialis. Height AFM images taken in water. (b-d) Progressive emergence of the calcitic layer trough the surface membrane. Deflection AFM images. Sequence of about 4 min. (e) Regrown fibrous calcite layer. Height AFM image. Inset, 2D-FFT map of the pattern formed by the single calcite crystals. (f) Height AFM image of calcite rhombohedra from the calcitic layer. (g) Profile along the transect (white line) in Fig. 6f. (h) High-resolution friction AFM image showing the lattice of a crystal of the calcitic layer. Crystallographic directions and the rectangular surface unit cell are indicated.
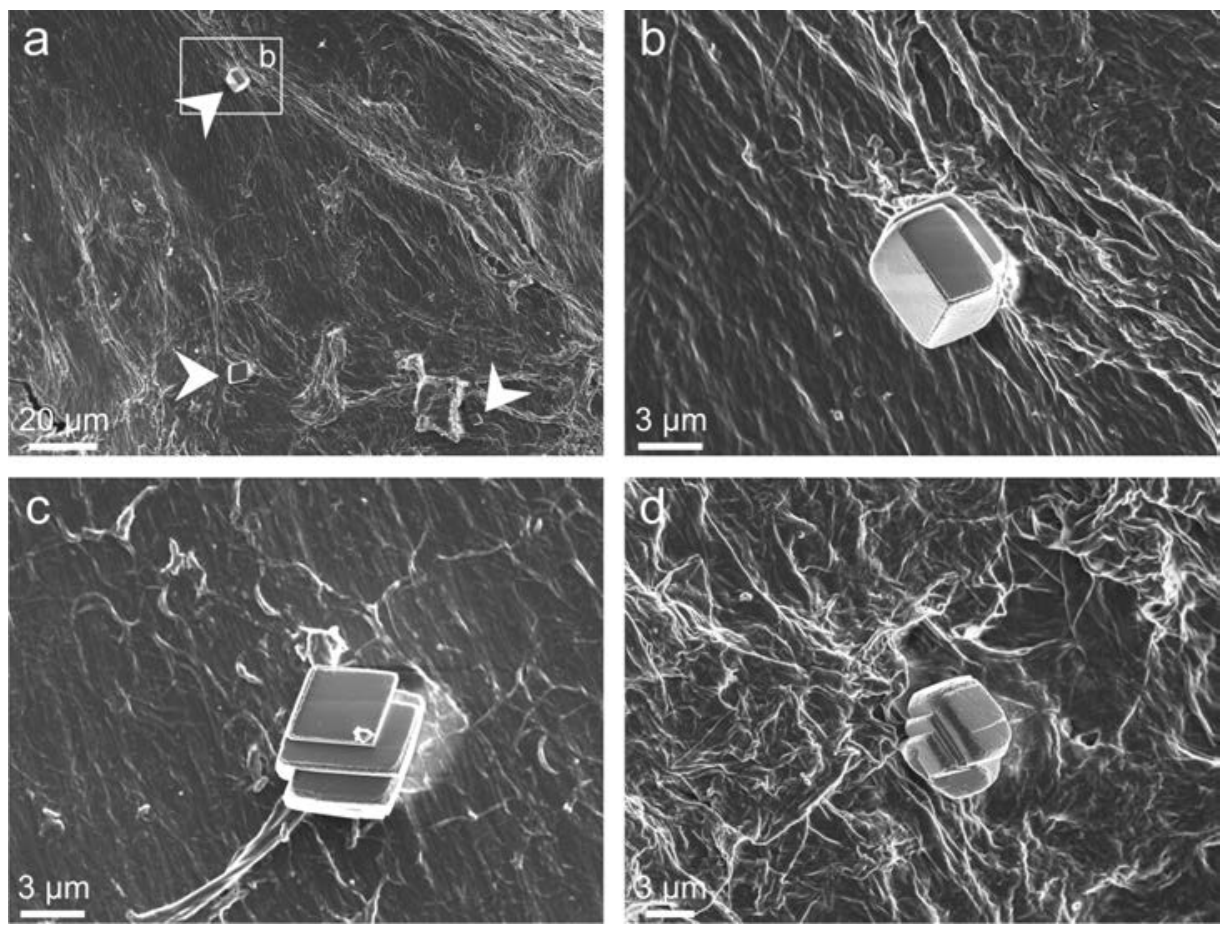

Fig. 7. Crystals grown on the internal surface of the decalcified surface membrane submerged in a supersaturated solution $\left(\beta_{\text {calcite }}=95.5\right)$. (a) General view to show the sparse distribution of calcite crystals (arrows). (b-d) Details of crystals. All of them grew onto their $\{104\}$ faces. The position of Fig. $7 \mathrm{~b}$ is indicated in Fig. $7 \mathrm{a}$ (frame).

solutions a) and b) described in subsection 2.4.2. In the areas scanned by AFM no crystal growth was observed over more than one hour of the experiment. The membrane was later allowed to dry out and observed under SEM. This examination allowed us to discern that very scattered rhombohedral calcite crystals (Fig. 7a), as well as some 
spherical crystals (with habits resembling those of vaterite; e.g. Ren et al., 2011) grew either during the experiment or the subsequent drying process. Except for one case in which the orientation was unclear, a total of 13 crystals observed had grown onto their $\{104\}$ surfaces (Fig. $7 b-d$ ).

\section{Discussion}

The outer calcitic shell layer of M. galloprovincialis and mytilids in general is made of long calcite fibres with terminal co-oriented $\{104\}$ rhombohedral faces (Fig. 1 and 3). The only exception found in this study is the observed shell of $M$. californianus in which terminal faces are seemingly either pinacoids or have extremely poorly developed $\{104\}$ faces (Fig. 3i). The fibres initiate at the internal periostracal surface (Fig. 4c) and reach the internal shell surface at an angle close to $45^{\circ}$ (Fig. $4 \mathrm{~d}-\mathrm{g}$ ). During growth new fibres are inserted within the aggregate, mainly by division of previous fibres but also by nucleation of new fibres on top of previous ones (Fig. 1c, $\mathrm{d}, 3 \mathrm{~b}-\mathrm{d}$ ).

The XRD pole figures show well defined 001 and 104 maxima (Fig. 5), which implies that all fibres have their $c$ - and $a$-axes co-oriented, although there is some degree of scattering in their orientation (about $10^{\circ}$ ) as deduced by the broadening of the pole figure maxima. There is always a 104 maximum centered on the pole diagram. This fits in with the SEM observation that all fibres have their rhombohedral faces co-oriented and that there is always one such face parallel to the internal shell surface. In addition, the small scattering of both the 001 and 104 maxima (except in M. californianus) implies that the co-orientation of fibres is strict. This coherent arrangement of crystals in a polycrystalline material is called a sheet texture. Our data agree with those of Dalbeck et al. (2006), who also found defined 001 and 104 maxima with EBSD on the shell layer of M. edulis. Feng et al. (2000) reached similar conclusions with TEM, although they described the existence of domains composed of several crystals with similar orientations, which we have not recognized here. The exceptional degree of orientation of the material is surprising. An even orientation of the $c$-axis of calcite fibres can easily be explained by selection by competition as is common in inorganic aggregates and has also been proposed for other biocrystal aggregates (e.g., Checa \& Rodríguez-Navarro, 2001). Nevertheless, the common orientation of the rhombohedral faces cannot be attributed to processes of this kind.

A peculiar feature of the fibrous prismatic calcitic layer of M. galloprovincialis is the existence of a surface membrane covering the biomineralisation compartment. The surface membrane was first observed by Mutvei (1972) in M. edulis. Remains of a similar membrane were also observed in C. chorus and M. edulis platensis suggesting that this structure is probably generally associated to the calcitic fibrous layer in the Mytilidae. This membrane is analogous to the surface membrane described in the nacres of gastropods and Nautilus (Nakahara, 1991; Checa et al., 2011), the main function of which is to prevent loss of organic molecules when the compartment is exposed, upon retraction of the mantle within the shell.

The surface membrane appears fibrous when it is criticalpoint desiccated (Fig. 1i), but much smoother in hydrated conditions (Fig. 6a). In TEM section, it is divided into horizontal nanolaminae (Fig. 4d-g). At the depressions between fibres the nanolaminae run with very little disturbance against the profiles of the fibres (Fig. $4 \mathrm{~d}-\mathrm{g}$ ), which implies that the nanolaminae are mostly absorbed by the growing crystals at the same time that the bivalve mantle secretes new laminae. Otherwise, the nanolaminae should be severely folded. The organic proteinaceous material can thus be included within the crystals, as intracrystalline matter, and/or condense around the calcite fibres forming the electron-dense organic sheaths observed and described by Grégoire (1961) and here (Fig. 4d-g). The surface membrane is in some way reminiscent of the translucent layer of the periostracum observed in anomalodesmatan and other bivalves (e.g., Salas et al., 2012). This periostracal layer condenses with growth into an outer dark (tanned) periostracal layer and, second, it also permits a flow of ions or particles across it during mineralization of intraperiostracal spikes at the boundary with the external dark layer (Checa \& Harper, 2010). Our AFM experiments show how calcite fibres are able to regrow and pierce across the surface membrane. This is a demonstration that the surface membrane is permeable to ions or nanoparticles.

A striking feature is the strict parallelism between the $\{104\}$ faces facing the interior of the shell and the surface membrane and its nanolaminae (Fig. $4 \mathrm{~d}-\mathrm{g}$ ). This suggests that the surface membrane somehow orients the rhombohedral faces, most probably due to a structural match between these crystal faces and the molecular groups (i.e., carboxylate groups) in the protein sheets. This is supported by our experiments of calcite growth onto the interior faces of isolated surface membranes, in which almost all calcite crystals nucleate and grow with their $\{104\}$ faces parallel to the interior of the surface membrane (Fig. 7). A molecular recognition mechanism is invoked to explain the nucleation of calcite crystals on the $\{104\}$ planes, which is otherwise a non-favoured nucleating surface [most commonly calcite nucleates on the (001) plane due to the ionotropic effect; Addadi \& Weiner, 1992], in particular a matching between these crystal surfaces and the organic surface layer (Mann et al., 1988).

It is also worth noting the high degree of plasticity of calcite fibres during growth. In B. azoricus and $C$. chorus we have observed that the fibres usually divide or initiate and are even able to bend or twist around their long axis (Fig. 3a-d, f). The same degree of freedom is observed in the calcite fibres forming the internal ribs of propeamussiids (Fig. 8). Checa et al. (2013) have recently shown how, due to the content of organic intracrystalline matter, the calcite crystals of the external layer of Pinctada margaritifera are 

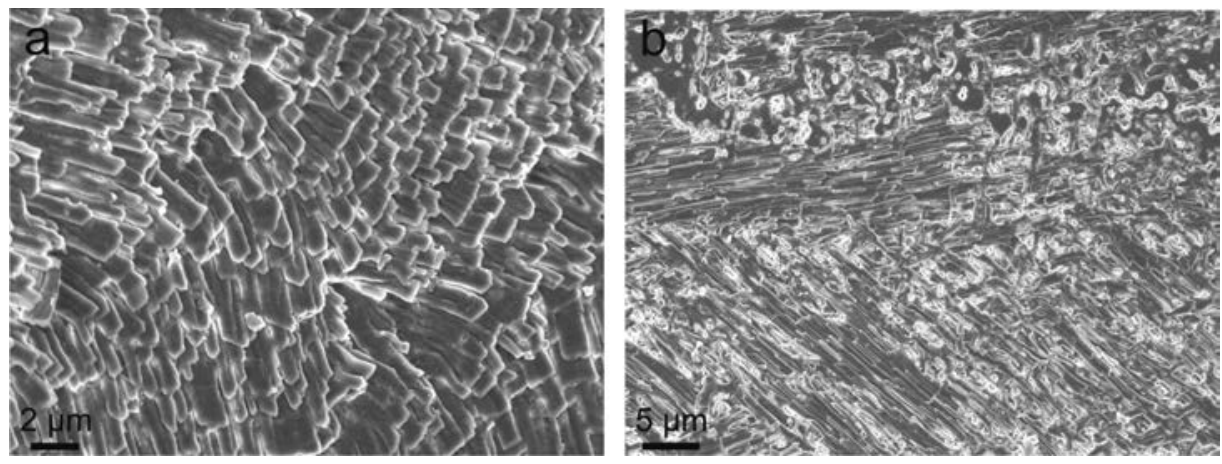

Fig. 8. (a, b) Two views of the winding calcite fibres forming the internal ribs of the scallop Parvamussium pauciliratum.

\section{a) Fitting by twisting}

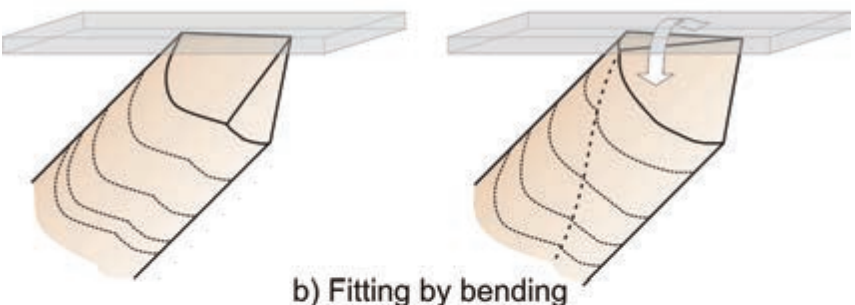

b) Fitting by bending

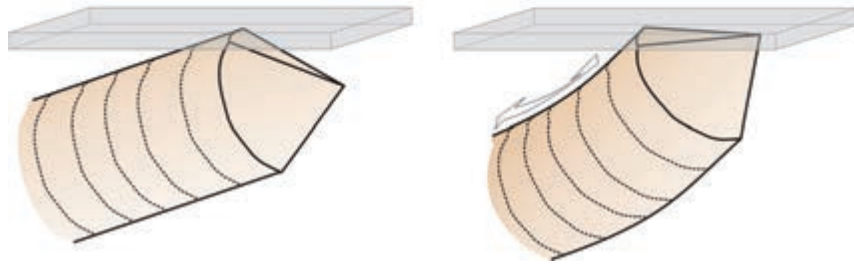

Fig. 9. Proposed model of "fibre locking" by the surface membrane. (a) A fibre in which the rhombohedral faces are all oblique to the surface membrane (left) twists around its long axis until a face becomes parallel to the surface membrane (right). (b) A fibre which is inclined to a low angle with respect to the surface membrane bends until one of its rhombohedral faces matches in orientation the surface membrane. A mixture of both processes is the most probable actual case.

able to both change the orientations of their axes during growth and split, in a way similar to the fibres of mytiloids.

In the case of the shells of mytilids, calcite fibres begin to grow onto the internal surface of the periostracum (Fig. 4c), and not onto the surface membrane. Later, new fibres are obtained either by splitting or by nucleation onto previous fibres; in any case, they retain the original orientation of the mother fibre by propagation of the crystal lattice in the former case or by re-growth in the latter case. Taking also into account the ability of the fibres to change their orientations and to split during growth, we hypothesize that the influence of the surface membrane probably resides in stabilizing the orientation of the fibres. The process is summarized in Fig. 9. In a twisting (e.g., Fig. 3c) and/or bending (e.g., Fig. 3c, f) fibre, once a rhombohedral face becomes parallel to the membrane, this face would be permanently "locked". Thus, fibre locking could be achieved either by random twisting (Fig. 9a), bending
(Fig. 9b) or a combination of both. This implies that the membrane is able to determine the orientation of fibres. This hypothesis would explain why the fibres of M. californianus, in which the $\{104\}$ faces are so incipiently or not developed (Fig. 4i), have their $a$-axes also poorly oriented. Fibre locking could be due to the above alluded process of recognition at the molecular level between the organic surface layer and the matching $\{104\}$ calcite planes. In this way, the observed general arrangement of the calcite fibres of M. galloprovincialis would soon be acquired due to the influence of the surface membrane, and transmitted via fibre division and re-growth.

Acknowledgements: The study was funded by projects CGL2010-20748-CO2-01, of the Spanish Ministerio de Ciencia e Innovación, and RNM6433 of the Andalusian Consejería de Innovación Ciencia y Tecnología, and by the Research Group 363 (latter Institution) as well as the European COST Action TD0903. C.M.P. also acknowledges the Centro Nacional de Microscopía Electrónica (Univ. Complutense Madrid), for the use of the AFM equipment. We are grateful to the following colleagues for supplying specimens: Paul Valentich-Scott (Santa Barbara Museum of Natural History, California, USA, provided specimens of $M$. californianus), Paul Tyler (National Oceanography Centre, Southampton University, UK; M. californianus) and Vreni Hausserman (Huinay Scientific Field Station, Chile; M. edulis platensis and $C$. chorus). Three anonymous reviewers also helped to improve the manuscript.

\section{References}

Addadi, L. \& Weiner, S. (1992): Control and design principles in biological mineralization. Angew. Chem. Int. Ed., 31, 153-169.

Carter, J.G. (1980): Environmental and biological controls of bivalve shell mineralogy and microstructure. in "Skeletal growth of aquatic organisms", D.C. Rhoads \& R.A. Lutz, eds. Plenum Press, New York and London, 69-113.

- (1990): Evolutionary significance of shell microstructure in the Palaeotaxodonta, Pteriomorphia and Isofilibranchia (Bivalvia: 
Mollusca). in "Skeletal Biomineralisation: Patterns, Processes and Evolutionary Trends, vol. 1", J.G. Carter, ed. Van Nostrand Reinhold Co, New York, NY, 135-296.

Carter, J.G. \& Seed, R. (1998): Thermal potentiation and mineralogical evolution in Mytilus (Mollusca; Bivalvia). in "Bivalves: an eon of evolution", P.A. Johnston \& J.W. Haggart, eds. University of Calgary Press, Calgary, 87-118.

Carter, J.G., Harries, P.H., Malchus, N., Sartori, A.F., Anderson, L.C., Bieler, R., Bogan, A.E., Coan, E.V., Cope, J.C.W., Cragg, S.M., García-March, J.R., Hylleberg, J., Kelley, P., Kleemann, K., Kř́̌ž, J., McRoberts, C., Mikkelsen, P.M., Pojeta, J., Jr, Tëmkin, I., Yancey, T., Zieritz, A. (2012): Illustrated glossary of the Bivalvia. Treatise Online, 48, 1-209.

Chateigner, D., Hedegaard, C., Wenk, H.-R. (2000): Mollusc shell microstructures and crystallographic textures. J. Struct. Geol., 22, 1723-1735.

Chateigner, D., Morales, M., Harper, E.M. (2002): QTA of prismatic calcite layers of some bivalves, a link to Trichite ancestrals. Mater. Sci. Forum, 408-412, 1687-1692.

Checa, (2005): Self-organisation of nacre in the shells of Pterioida (Bivalvia: Mollusca). Biomaterials, 26, 1071-1079.

Checa, A.G. \& Harper, E.M. (2010): Spikey bivalves: Intra-periostracal crystal growth in anomalodesmatans. Biol. Bull., 219, 231-248.

Checa, A.G. \& Rodríguez-Navarro, A.B. (2001): Geometrical and crystallographic constraints determine the self-organization of shell microstructures in Unionidae (Bivalvia: Mollusca). Proc. R. Soc. London B, 268, 771-778.

Checa, A.G., Rodríguez-Navarro, A.B., Esteban-Delgado, F.J. (2005): The nature and formation of calcitic columnar prismatic shell layers in pteriomorphian bivalves. Biomaterials, 26, 6404-6414.

Checa, A.G., Okamoto, T., Ramírez, J. (2006): Organization pattern of nacre in Pteriidae (Bivalvia: Mollusca) explained by crystal competition. Proc. R. Soc. B, 273, 1329-1337.

Checa, A.G., Esteban-Delgado, F.J., Rodríguez-Navarro, A.B. (2007): Crystallographic structure of the foliated calcite of bivalves. J. Struct. Biol., 157, 393-402.

Checa, A.G., Cartwright, J.H.E., Willinger, M.-G. (2011): Mineral bridges in nacre. J Struct. Biol., 176, 330-339.

Checa, A.G., Bonarski, J.T., Willinger, M.G., Faryna, M., Berent, K., Kania, B., González-Segura, A., Pina, C.M., Pospiech, J., Morawiec, A. (2013): Crystallographic orientation inhomogeneity and crystal splitting in biogenic calcite. J. R. Soc. Interface, 10, 20130425.

Dalbeck, P., England, J., Cusack, M., Lee, M.R., Fallick, A.E. (2006): Crystallography and chemistry of the calcium carbonate polymorph switch in M. edulis shells. Eur. J. Mineral., 18, 601-609.

Esteban-Delgado, F.J., Harper, E.M., Checa, A.G., RodríguezNavarro, A.B. (2008): Origin and expansion of foliated microstructure in pteriomorph bivalves. Biol. Bull., 214, 153-165.

Feng, Q.L., Li, H.B., Pu, G., Zhang, D.M., Cui, F.Z., Li, H.D. (2000): Crystallographic alignment of calcite prisms in the oblique prismatic layer of Mytilus edulis shell. J. Mater. Sci., 35, 3337-3340.

Grégoire, C. (1961): Structure of the conchiolin cases of the prisms in Mytilus edulis Linné. J. Biophys. Biochem. Cytol., 9, 395-400.

Harper, E.M., Checa, A.G., Rodríguez-Navarro, A.B. (2009): Organization and mode of secretion of the granular prismatic microstructure of Entodesma navicula (Bivalvia: Mollusca). Acta Zool. 90, 132-141.
Hedegaard, C. \& Wenk, H.R. (1998): Microstructure and texture patterns of mollusc shells. J. Moll. Stud., 64, 133-136.

Horcas, I., Fernández, R., Gómez-Rodríguez, J.M., Colchero, J., Gómez-Herrero, J., Baró, A.M. (2007): WSXM: a software for scanning probe microscopy and a tool for nanotechnology. Rev. Sci. Instrum., 78, 013705.

Lowenstam, H.A. (1954a): Environmental relations of modification compositions of certain carbonate secreting marine invertebrates. Proc. Natl. Acad Sci. USA, 40, 39-48.

- (1954b): Factors affecting the aragonite:calcite ratios in carbonate-secreting marine organisms. J. Geol., 62, 284-322.

Mann, S., Heywood, B.R., Rajam, S., Birchall, J.D. (1988): Controlled crystallization of $\mathrm{CaCO}_{3}$ under stearic-acid monolayers. Nature, 334, 692-695.

Marin, F. (2003): Molluscan shell matrix characterization by preparative SDS-PAGE. Sci. World J., 3, 342-347.

Mutvei, H. (1972): Formation of nacreous and prismatic layers of Mytilus edulis L. (Lamellibranchiata). Biomineralisation, 6, 96-100.

Nakahara, H. (1991): Nacre formation in bivalve and gastropod molluscs. in "Mechanisms and Phylogeny of Mineralization in Biological Systems", S. Suga \& H. Nakahara, eds. Springer, Berlin, 343-350.

Parkhurst, D.L. \& Appelo, C.A.J. (1999): User's guide to PHREEQC (version 2)- A computer program for speciation, reaction-path, 1D-transport, and inverse geochemical calculations. US Geol. Surv. Water Resour. Inv. Rep, 99-4259, 1-312.

Pina, C.M., Miranda, R., Gnecco, E. (2012): Anisotropic surface coupling while sliding on dolomite and calcite crystals. Phys. Rev. B, 85, 073402.

Ren, A., Feng, Q., Bourrat, X. (2011): Effects of additives and templates on calcium carbonate mineralization in vitro. Micron, 42, 228-245.

Rode, S., Oyabu, N., Kobayashi, K., Yamada, H., Kühnle, A. (2009): True atomic-resolution imaging of $(101 \overline{4})$ calcite in aqueous solution by frequency modulation atomic force microscopy. Langmuir, 25, 2850-2853.

Rodríguez Navarro, A.B. (2006): XRD2DScan a new software for polycrystalline materials characterization using two-dimensional X-ray diffraction. J. Appl. Crystallogr., 39, 905-909.

Salas, C., Marina, P., Checa, A.G., Rueda, J.L. (2012): The periostracum of Digitaria digitaria (Bivalvia: Astartidae): Formation and structure. J. Moll. Stud., 78, 34-43.

Schütte, J., Rahe, P., Tröger, L., Rode, S., Bechstein, R., Reichling, M., Kühnles, A. (2010): Clear signature of the $(2 \times 1)$ reconstruction of calcite (1014). Langmuir, 26, 8295-8300.

Stipp, S.L.S. (1999): Toward a conceptual model of the calcite surface: hydration, hydrolysis and surface potential. Geochim. Cosmochim. Acta, 63, 3121-3131.

Taylor, J.D. \& Kennedy, W.J. (1969): The shell structure and mineralogy of Chama pellucida Broderip. Veliger, 11, 391-398.

Wada, K. (1961): Crystal growth of molluscan shells. Bull. Natl. Pearl Res. Lab, 7, 703-828.

Wise, S.W. (1970): Microarchitecture and mode of formation of nacre (mother of pearl) in pelecypods, gastropods and cephalopods. Eclogae Geol. Helv., 63, 775-797.

Received 24 July 2013

Modified version received 10 December 2013

Accepted 14 January 2014 